\section{ASIAN AESTHETICS \\ ALIVE - THE \\ VISUALISING POWER \\ OF CONTEMPORARY \\ NATIONAL STYLE}

\section{Mirja Thaulow ${ }^{1}$}

\begin{abstract}
In these times of globalization, it sometimes appears as if all cultural particularrities are about to vanish. But, at the same time, a strong current of public affection for national values can be detected all over the world, especially in the visual culture. Here, an international aesthetic of the national is being developed and it can be termed as "the style of the national" or "national style". By employing this term in the analysis of national pictures from two very different Asian countries, Thailand and Uzbekistan,this article will show that Asian aesthetics are very much alive in the present.
\end{abstract}

A paradox often appears in writings on globalisation - the fact that it promotes a lot of regionalist reactions in the cultural sphere around the world. Some people would reject these cultural productions as artificial ${ }^{2}$, but as they are welcomed by ordinary people fulfilling their needs for an unique identity in the

Research student and assistant teacher at the Department of Art History, University of Copenhagen, Denmark.

${ }^{2}$ See for example: Masao Miyoshi, "A Borderless World?", Critical Inquiry (19/ 1993). modern world it is my opinion that the new cultural productions become real. A new sense of aesthetic genuineness is invested in these productions as visual signs of nationality. Therefore I find it relevant to discuss the appropriation of the term "national style" in an aesthetic investigation. I am looking into this issue as I am doing comparative research in the field of national visual cultures, especially in Asia. Two of my case studies are the visual cultures of Thailand and Uzbekistan.

I will start by confronting the notion of nationalism in the theory of both sociology and art history. After this I will go on to present the fascinating pictorial matter of this investigation.

\section{Nationalism as concept and vision}

I would like to start out by saying that I am not using the term "nationalist" as a negative term. I see it as a broad concept offering cultural identity to many people around the world.

According to sociologist David McCrone there are two poles in the study of nationalism: the modernist approach that views nationalism primarily as a construction and the ethnic approach that focuses on the cultural roots of nationalism and how they are mobilised. The latter approach is valuable because it can explain the emotional power of the nation's history. The problem is the discontinuity between past and present - if a nation does not have any inheritance arguably it invents one. It therefore turns out to be a matter of degree, as to the value to be placed on each approach, and they 
might not be that different after all ${ }^{3}$. In my opinion nationalism will always be a construction but it is given life in those cases where people embrace it and use it as an identity in their everyday lives. It is realised through their practical usage and becomes a reality in its own right. Different kinds of pictorial media can play a significant part in this process as I will soon demonstrate.

Keith Moxey, a critical representative of the so called "new art history", points out how the founders of "traditional art history"used the principle of style to detect the progress of spirit through history in a way that corresponded to the nationalist politics of Europe in the 19 th and 20th centuries. They were inspired by the Hegelian philosophy of history that, according to Moxey, treated history as a history of nations instead of individuals. It was through nations that the spirit, or Volksgeist, found its historical manifestation with different peoples ${ }^{4}$. What Moxey is criticising in the art historical construction of "national style" is that the present is projected onto the past. In the following case studies I am going to use the term "national style", but in the sense of its own projection of the past onto the present. This operation is carried out by the pictures themselves and it can be termed "historic eclecticism". It is not only the writings on history that construct the national style, the pictures join in this discourse. The national styles that are described in this investigation are alive today, as synthetic constructions, but realised through

\footnotetext{
${ }^{3}$ David McCrone, The Sociology of Nationalism, New York 1998, p. 16.
}

practical usage - as conscious reactions to other tendencies like the borderless ideologies of capitalism and communism. I will look at style as a conscious instrument of the nationalist tendency as an international phenomenon alive in a globalised world.

\section{The mural paintings of a Thai temple}

In 1984-1987 the Wat Buddhapadipa in London was decorated by Thai artists Chalermchai Kositpipat and Panya Vijinthanasarn (and their assistants) with mural paintings depicting traditional scenes of Thai Buddhism mixed with new techniques and untraditional subject matter (fig. 1). This approach can be observed as an international tendency working in another direction than modernist art in both form and purpose. The style of the national message is using traditional rhetoric combined with citations from contemporary culture and an affective way of confronting its audience.

Apinan Poshyananda, an art historian of Thai art, points out that in the paintings of Wat Buddhapadipa the Buddhist faith is imagined outside the national borders. Margaret Thatcher and Ronald Reagan, alongside more funny characters from the cultural industry, are depicted within scenes of earthly and evil matters, while the royal family of Thailand is depicted in scenes of royal and divine activities. It becomes a room for promotion of

\footnotetext{
${ }^{4}$ Keith Moxey, Art History's Hegelian Uncounscious: Naturalism as Nationalism
} 
national culture ${ }^{5}$. In the divine placement of the royal family opposite the chaotic appearance of the foreign leaders we see an example of the artist Panya's ability to mix conventional allegory with contemporary elements. The joined message of Thai Buddhism and Thai monarchy is being put forward as an ideal in opposition to the chaos of the international world. This is effectively portrayed through the composition of the picture as a mirroring of the two scenes along a central axis.

The use of traditional medium (mural painting) and traditional style is likely to bring along a traditional function of Buddhist art: that the goal is not the narrative or the aesthetic pleasure in itself, but the fact that these experiences give religious merit to the donor, the creator, and the spectator. In this process the contemporary message of the renewed iconography is easily accepted in the light of pursuing religious merit. A new kind of merit can be expected to come along and that is the patriotic merit giving a veneration back to the national message as it has always been the case with the Buddhist message.

This may not call for the self conscious position assumed by Apinan Poshyananda when he calls Panya's art "postmodernist" ${ }^{\text {. He might think }}$ primarily of the artist's position, but what if the spectator is not conscious of this new self consciousness, but applies the ways of looking from traditional art?

${ }^{5}$ Apinan Poshyananda, "Nationalism and Sexuality à la Thai", in: Contemporary Art in Asia: Traditions/Tensions (Asia Society Galleries), New York 1996, p. 106.
Apinan Poshyananda is asking himself if it is possible to talk about postmodernism or reviving of tradition, and he concludes by choosing the former by way of the argument of self-consciousness; I do not think this conclusion should be taken for granted. This dilemma between postmodernist distance and traditional reviving is central to the whole discussion of visual nationalism today. My position is that it does not have to be one thing omitting the other referring to my position in the theory of nationalism - the visual image of the national idea can be created consciously by the artist who gives it an appropriate expression for the new times. But in order to realise this vision and bring it to life the reaction of the spectators plays a significant part. If the message reaches them in an emotional way instead of talking to their conscious minds the reaction of realisation is likely to be stronger. I will return to this emotional side of the pictures when confronting the term "national style" aesthetically.

\section{A wall painting in an Uzbek museum}

In Tashkent, the capital of Uzbekistan, the Museum of History contains a giant wall painting carrying the name "Vault of Eternity" (fig. 2). It was painted by B. Jalal in 1995.

The painting is visualising the new nation of Uzbekistan ${ }^{7}$ by way of a

\footnotetext{
${ }^{6}$ Apinan Poshyananda, "Thai MODERNism to (post?) modernISM", 1970s and 1980s, in: Modernity in Asian Art (ed. Clark), Singapore 1992, p. 230.
} 
collection of symbolic elements from past and present. There are several levels in the composition which is built up around a pyramid-shaped core. At the lower level we see traditional figures as types: holy men, scientists, artists, and their muses. At the second level three figures are seated at a table, they are actual characters from the time of the great Timurid empire, a period which is venerated as a central point of focus in the historiography of the new nation. Tamerlane, the founder of the Timurid dynasty, is horseback riding over their heads in full armour, ready to conquer the modern world. His helmet is almost penetrating the shining centre of the painting: The Koran, the holy book of Islam. The book is surrounded by shimmering light, symbolic of Allah himself, and one of the only ways to picture him. The light is carried upwards and continues into the picture of the Uzbek president, Islam Karimov. He is hovering over an historicist building from Soviet times that could very well be the Museum of History seen from the outside. A golden globe showing the side of Asia is seen in front of him and the Uzbek national emblem is behind him. The head of the president forms the top of the central pyramid and behind him the eternal wheel of the Zodiac is spinning, framed by a chain of stars.

Assuming that the spectators are to look at the pictures in the way of a work of socialist realism from the recent Soviet era the president is at the top of the power pyramid, as a cult figure. $\mathrm{He}$ is

\footnotetext{
${ }^{7}$ Uzbekistan was never an independent country before 1991 when the Soviet Union fell apart.
}

the father of the nation re-allowing, but controlling, religion (the Koran); reglorifying and newly creating Uzbek history (the selective compilation of historical figures and the building of the Museum of History). But the situation of the viewer is not that simple.

Olivier Roy, a French social scientist of Central Asian relations, has studied the many changes occurring after the independence in 1991. For example Roy studied the phenomenon of leaders who a few months earlier had been repeating the slogans from Moscow, now becoming eager supporters of a nationalism that was more hostile towards Russia and open towards the West. The Uzbek president, Islam Karimov, was also the leader of the Uzbek communist party in Soviet times. Are the leaders of the Central Asian republics, unchanged communists who want to build little Soviet republics, or did the collapse of the Soviet Union simply reveal the continuous existence of a traditional society with its new potentates, clanism, and ethnic fighting going back to the beginning of times? Do we see something new here, or something old? Roy argues that it is neither possible to see the situation as a return to pre-soviet past or as neosovietism: the new nations have to be taken seriously themselves. Their independence was sudden and there were no memory of a lost nation, but in the minds of their populations the Central Asian nations have a solid and tangible reality ${ }^{8}$.

\footnotetext{
${ }^{8}$ Olivier Roy, The New Central Asia. The Creation of Nations, London 2000, pp. VII-VIII.
} 
This practical way of approaching the situation, from the point of view of the people living in it, is supportive of the view on nationalism carried forward in the beginning. The construction of a visually articulated nationalism can be deconstructed and analysed as drawing on several traditions, but the viewer can make the synthesising operation of uniting them as a reality in the present. Here it will be demonstrated by using a broad definition of style containing the descriptive concepts of eclecticism and affective form.

\section{Style as visuality and content}

The colours of the paintings in the Wat Buddhapadipa are brighter than in the old temples because chalk and tempera are replaced by acrylic and spray-paint. The shining colours create a pulsating rhythm as the viewer is bombarded with purple, pink, cobalt, and gold . Combined with the renewal of iconography the Buddhist scenes are united with the reality of the present in a gay atmosphere of modern cartoons, in particular Asian cartoons with their intriguing aesthetics of stylised form and bright colours. It is an obvious renewal of style, not just iconography, and the artist Chalermchai leads the way. His neo-Buddhist style is very popular, for example in street shops selling mass produced Buddhist and royalist pictures. Looking at Chalermchai's style of painting it is obvious that he has maintained the basic features of the traditional style of Buddhist painting,

\footnotetext{
${ }^{9}$ Apinan Poshyananda, Modern Art in Thailand, New York 1992, p. 199.
}

but the colours have at the same time the arousing sharpness of the acrylic paint and the shimmer of fading rainbows which promotes an affective condition of ecstasy. A style with a temper that is both static and foaming wild offering a dreamlike escape from reality to the viewer.

Traditional Buddhist painting has a mystical function besides the moral function of merits: the symbolic and presumed magical power that bring forward the presence of the Buddha.

This sacred presence inspires good thoughts and actions, consoles sad thoughts, brings luck, and keeps away evil $^{10}$. The escape from reality through aesthetic contemplation with a higher truth as goal by way of Buddhist mysticism might be transferred to the nationalist mysticism today. The inward looking style is promoting the notion of Thai culture through the nostalgia of traditionalism and the picturing of the King alongside the Buddha so that they can be made present in each others realities.

In the Uzbek painting there is a larger composition around the central pyramid core: the lower historical level surrounded by chains of stars is contrasted with the upper circular shape of the Zodiac - the Koran and the president connects the past and the present in front of the blue sky of the universe. A large amount of different

\footnotetext{
${ }^{10}$ Nananda Chutiwong, "The Role of Narrative Sculpture and Painting in Thailand", in: Functions and Meaning in Buddhist Art, Groningen 1995, p. 171.
} 
pictorial elements loaded with symbolic meaning are spreading towards each side as circular formations. One side is dominated by sculptures from different civilisations (ancient Greek, Buddhist, etc.) which have all been in contact with Central Asia as the cultural connection point between East and West through history. The other side contains mythological figures, primarily animals, from the realm of miniature painting. Legendary creatures from pre-Islamic Persia that continued to survive in Timurid art.

The eclectic style of the painting is obvious: as the artist incorporates iconographic elements from different pictorial traditions many stylistic features are mixed as well - ones belonging to Greek art, middle- and far eastern art, and Persian Central Asian art. It is a classicist stone style on one side against a sensual explosion of colours on the other. The style of the central pyramid core might be more concise and less symbolic, but where does it come from? There is a certain linearity and detailed delicacy which definitely relates to miniature painting, but a further degree of naturalism points in the direction of Soviet socialist realism, both in its portraits supporting the leaders as cult figures, but also in its inspiration from the colourful style of the Intinerists, a Russian school from the end of the 19th century. A sort of fairy-tale style connects the arts of illustration and painting and also a style of Russian nationalism for the people. Socialist realism focused on the use of eclectic style for an ideological purpose $^{11}$. These aesthetics can be seen to be continued by Uzbek art today, creating its own national style by way of visual eclecticism and in this way establishing a tradition.

One of the traditional formal elements worth noticing is the mosaic: the picture plane is sometimes crystallised into small coloured squares. This brings a shimmering effect to the painting, but it can also be associated with a national style as the mosaic is a traditional art form in Central Asia. In this way style can act as content. The fact that the large wall painting has an ornamental shape also calls for an alternative way of looking at it: not as a perspective box with ordered principles of space - not as a window to the world. It looks more like a decorative frame as seen in the calligraphic art which is shown on the writing board of the holy man in the middle of the lower level. The traditional way of contemplating the abstract beauty of the ornament consists of the act of lifting the mind to a higher sphere which is not limited by the existentialism of the three-dimensional, but is two-dimensional and spiritual ${ }^{12}$.

In this context the picture is not viewed as photographic reality, but as visual stimuli of another character, with the contemplation of a higher truth as its goal. This old use of an affective visual strategy can be combined with a newer use of the affective style by socialist realism: the bombardment of the senses by way of extreme forms such as very

"Boris Groys, Gesamtkunstwerk STALIN, Wien 1988/1996, pp. 44-56.

${ }^{12}$ Keith Critchlow, Islamic Patterns, London 1976 , p. 8. 
large scales in order to present the ideological message as extremely real, more real than normal reality ${ }^{13}$. The painting has a monumental size and if it is viewed from a central perspective, the viewer is pressed backwards when moving up the stairs beneath it, overwhelmed and ready to surrender.

The ornamental composition offers another kind of perspective - a perspective coming forward and approaching the viewer: the shining centre with the Koran is coming out, it does not draw back into the fictitious space of a representation of threedimensional reality. In the Islamic art of calligraphic ornamentation, the centre forms the most important place, usually reserved for the name of God, the core of everything. In this way the picture contains two compositions, one in favour of the Koran and one in favour of the president, whereby several meanings are connected in the rhetoric of visual style. Both characters play a significant part in the vision of the Uzbek nation along with the glorious elements of history.

Comparing the national pictures from the two countries, several similarities appear in the use of visual rhetoric. In both cases national styles are being constructed inside the pictures themselves: past and present are being connected with pictorial immediacy by way of eclecticism, iconographically as well as stylistically. When analysed, there are discrepancies in the

${ }^{13}$ Alla Efimova, "To Touch on the Raw. Aesthetic Affections of Socialist Realism", Art Journal (56/1997), pp. 72-77. representations, but in the pictorial space different views can exist side by side and can even support each other. But in order to get the spectators engaged in the act of looking constructively and thereby realising the national vision, they have to be stimulated emotionally. This can be done by way of an affective style. In both pictures we see this in the way that they draw on affective traditions from their cultural backgrounds. This could be the dreamlike quality of the Buddhist style, the abstract aesthetics of the Islamic ornament, or the extreme forms of socialist realism. Another way of using the value of affection is related to the use of different kinds of pictorial media, both traditional and modern. This is what I will look into in the last part of this paper.

\section{The use of media in a broader perspective.}

The royalist pictures of the Thai temple are made in the traditional medium of the art of Thai Buddhism, mural paintings. As I mentioned earlier this could bring along with it the traditional function of this art to the benefit of the realisation of the national message.

The Uzbek painting in the Museum of History is a large wall painting, a medium which recalls the gigantic dimensions of socialist realist art. This is also the case with two equestrian statues of the primary historic national symbol, Tamerlane, in the cities of Samarcand and Tashkent. They are placed on the central squares of these cities instead of the statues of Marx and Lenin: a very conscious way of marking 
the new era visually in the public space of the cities. It is a bit strange then to use the same kind of pictorial media, especially statues, which did not play a role in Islamic Central Asia before the Soviet. But the statue is not entirely Soviet either; it is the official and representative media of nationalist art as an international phenomenon developed primarily in the 19th century. It was imported everywhere, and does not belong to just one nation. The fact that Tamerlane is either riding a horse or sitting on a throne and the fact that his helmet has been turned into a crown, shows more adherence to this traditional kind of visual nationalism than to the art of socialist realism.

Uzbekistan obtains it now, being a new nation. Thailand started using the equestrian statue in the big era of nationalism 100 years ago when the internationally minded King Chulalongkorn had a statue made of himself riding a horse. This statue is still at the Royal Plaza in Bangkok, but it has got a new meaning today as a large group of people have made it into a shrine. They offer flowers, incense, whisky, and candles to the former king as a divine protector of the Thai nation against pressures from the outside world. Present day affective nationalism is changing the original meanings of the dry and rationalist style of 19 th century visual nationalism.

To grasp how widely the pictorial arts are spreading the national message in society, it is necessary to look into the popular visual culture in the streets and in the private homes as it functions as a natural part of people's lives. The big group of popular pictorial matter also has another function: it connects the world of traditional culture with the present actuality of globalisation by way of modern media. Large billboards in both Thailand and Uzbekistan place national icons in the middle of busy city life in the pictorial rhetoric of commercials. It is a modern form that can bring national style further, also in dialogue with the traditional tendency. Popular mass-produced pictures also make use of the affectionate value and function of traditional media. In Thailand portraits of the royal family are pictured in the Buddhist media of amulets, and their glittery paintings are placed on home altars. There is a long tradition of combining the religious with royalty in Thailand, but this tendency gets a new face in the affective visualisation of Thai culture in a globalised world.

In Uzbekistan portraits of national symbols, such as the president and Tamerlane, are mass produced in carpet form which is a very traditional medium of central Asia. The art of the portrait carpets and their affective value as a traditional medium were also used by the Soviet visual rhetoric ${ }^{14}$. According to the Uzbek journal San 'at, the portrait carpet goes back to the tradition of picture carpets developed in $16^{\text {th }}$ century Persia with inspiration from miniature painting ${ }^{15}$.

\footnotetext{
${ }^{14}$ The portrait of Stalin was woven into traditional carpets, see Matthew Bown, Socialist Realist Painting, London 1998, pl. 325.

15 "A Carpet with Amir Timur's Portrait", San'at - Journal of the Academy of Art of Uzbekistan (1/1999), pp. 32-33.
} 
The affective and intimate way of popular consumption could also be put into work in front of the big official pictures which are making a coherent system of it all - the two groups complement each other by way of the spectators they share. The modern media of popular culture connect all this with the everyday life of big cities and the actuality of economic globalisation competing with it on its own terms by way of the visual rhetoric of commercials.
The pictorial arts have the power to maintain cultural uniqueness in a world of change, because the act of visualising can connect different elements in new harmonies and stimulate the emotions to realise this vision in real life. In this way, the age-old traditions of Asian art can be kept alive today through the aesthetic operations of national styles. 


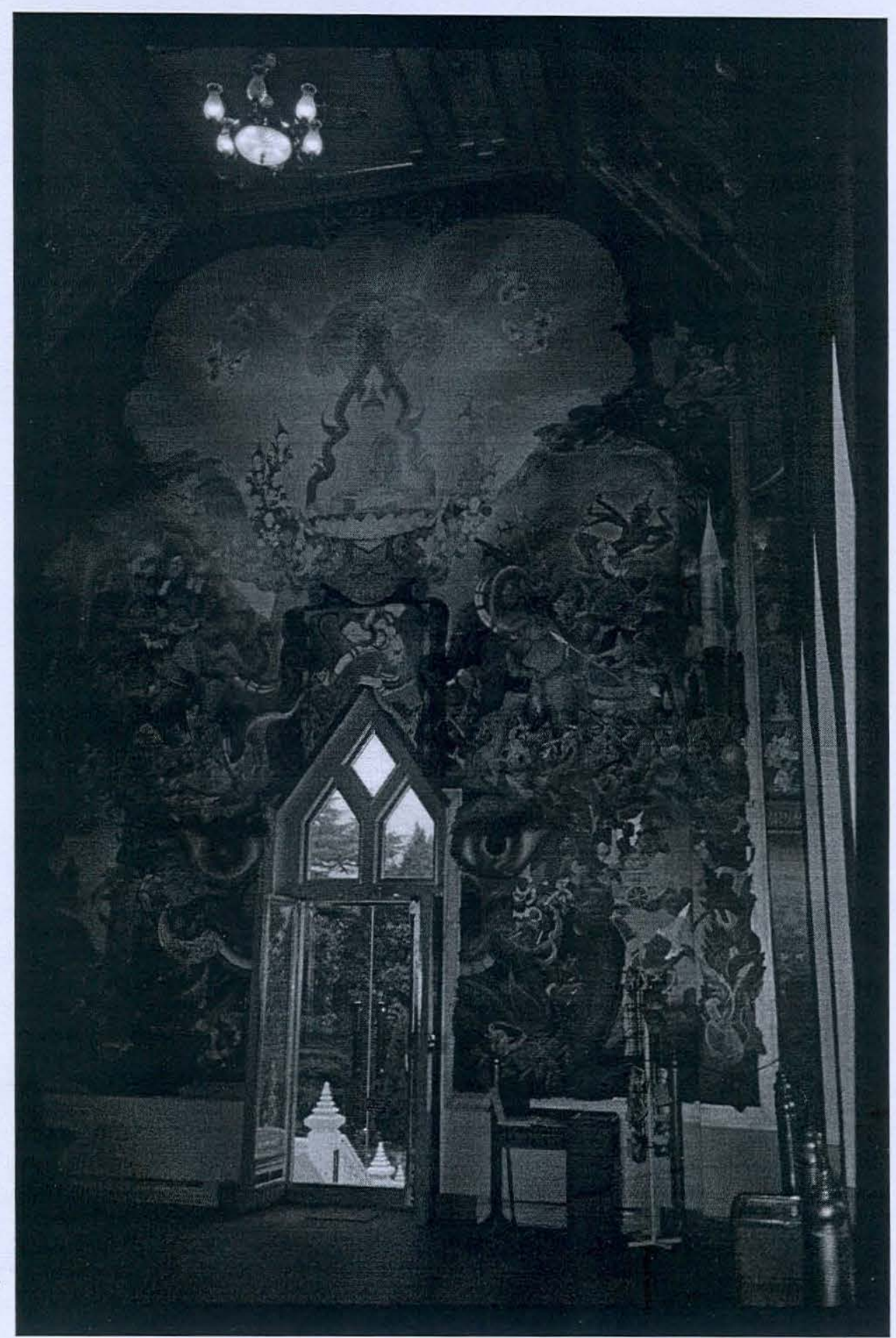

Fig.1 Mural paintings at Wat Buddhapadipa in London painted by Chalermchai Kositpipat and Panya Vijinthanasan (and their assistant) 
Asian Aesthetics Alive

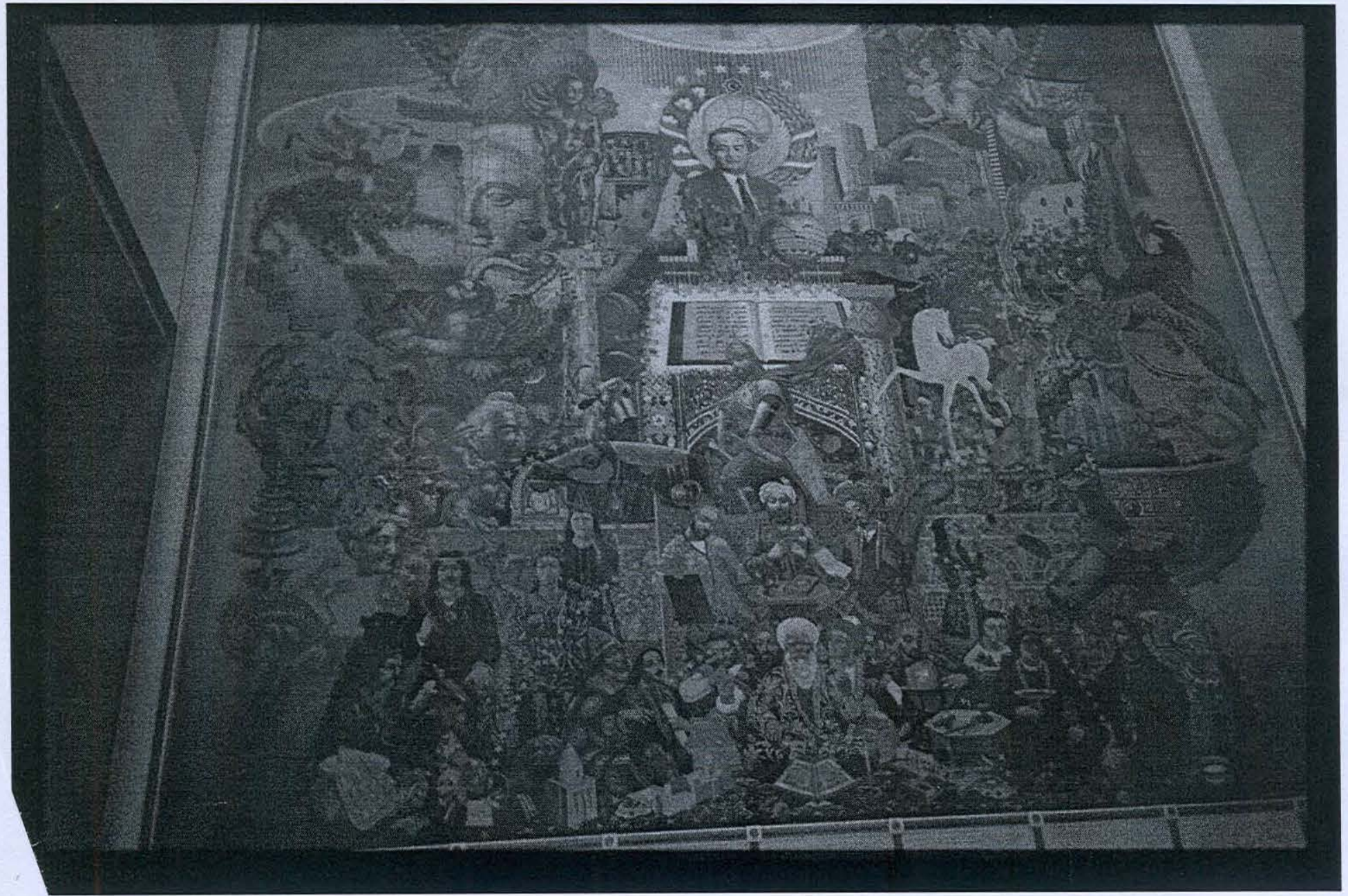

fig.2 "Vault of Eternity" painted by Jalal in 1995. 